\title{
Prevalence and Risk Factors for Low Back Pain in 1,355 Young Adults: A Cross-Sectional Study
}

\author{
Sudhir Ganesan ${ }^{1}$, Anita Shankar Acharya ${ }^{2}$, Ravi Chauhan ${ }^{1}$, Shankar Acharya ${ }^{1}$ \\ ${ }^{1}$ Department of Spine Surgery, Sir GangaRam Hospital, New Delhi, India \\ ${ }^{2}$ Department of Community Medicine, Lady Hardinge Medical College and Associated Hospitals, New Delhi, India
}

\begin{abstract}
Study Design: Cross-sectional study.
Purpose: To evaluate the prevalence and various risk factors for low back pain (LBP) in young adults in India.

Overview of Literature: LBP is an emerging problem in adolescents, with an incidence that is the highest in the third decade of life worldwide. Various risk factors such as obesity, smoking, family history, stress, and exercise have been described in the literature. This study was conducted because of paucity of data in the Indian literature.

Methods: A total of 1,355 (741 males and 641 females) young Indian Administrative Service aspirants and medical postgraduate aspirants aged 18-35 years were enrolled in the study. The subjects completed a detailed, semi-structured questionnaire that gathered data regarding their sociodemographic profile and factors considered to be risk factors for LBP. Anthropometric measurements, including height and weight, were measured and body mass index was calculated.

Results: Most subjects (90.6\%) were aged 20-29 years (mean, 24.49; range, 18-35 years). Results indicated that the following factors were associated with LBP in young adults: marital status, previous history of spine problems, strenuous exercise, job satisfaction, monotony, stress, daily number of studying hours, and family history of spine problems $(p<0.05)$. However, age, sex, smoking, alcoholism, coffee intake, mode and duration of travel, diet, frequency of weightlifting, wearing heels, studying posture, and frequency and type of sports activities were not associated with LBP.

Conclusions: The study identified various modifiable and non-modifiable risk factors that precipitated LBP in young adult Indians. Identifying these risk factors at an early stage will prevent LBP progression to a chronic disease state, thereby improving an individual's quality of life and increasing productivity.
\end{abstract}

Keywords: Low back pain; Young adults; Risk factors

\section{Introduction}

Low back pain (LBP) is experienced in $60 \%-80 \%$ of adults at some point in their lifetime. Andersson [1] estimated the annual worldwide LBP incidence in adults to be $15 \%$ and the point prevalence to be $30 \%$. Papageorgiou et al. [2] stated that at least $50 \%$ of adults would have experienced an LBP episode. Some studies have demonstrated that LBP is one of the most common cause of visits to a physician [3] and that men and women are equally affected by LBP [4]. The literature shows that $30 \%$ of adolescents worldwide experience at least one LBP episode [4]. Various studies found that LBP is a very common problem among adolescents, with an incidence that is the highest

Received Dec 28, 2015; Revised Dec 18, 2016; Accepted Jan 10, 2017

Corresponding author: Sudhir Ganesan

Department of Spine Surgery, Sir GangaRam Hospital, Old Rajinder Nagar, New Delhi - 110060, India

Tel: +91-9962277126, Fax: +91-444285000,E-mail: sudhir_axon@yahoo.co.in 
in the third decade of life [5]. Some authors proposed that LBP in young adults and children may occur because of growth spurts and increased physical activity [6]. In contrast, Fairbank et al. [7] revealed that students with back pain were more likely to be sports avoiders than their counterparts who were involved in sports. Young adults who experienced LBP at the age of 14 years had an increased incidence 25 years later compared with those who did not experience LBP at age 14 years [8]. Therefore, preventing and avoiding LBP during early adolescence can prevent LBP progression, and thus, can decrease the associated morbidities. However, to prevent LBP, the associated modifiable and non-modifiable risk factors must be identified. Previous studies have demonstrated that high body mass index (BMI) is associated with an increased LBP incidence [9]. In addition, Webb et al. [9] revealed that hereditary plays a vital role in LBP occurrence and that a positive family history has a strong correlation with LBP incidence [10]. Risk factors for LBP are not limited to physical factors; psychosocial factors such as stress, anxiety, depression, and monotony are also potential risk factors for LBP [11-14]. These risk factors can result in the progression from an acute LBP episode to a chronic problem.

Although various studies in the literature have examined the incidence, prevalence, and risk factors for LBP in young adults, there is a paucity of data regarding this topic in young Indian adults. Given this gap in the literature, we conducted a cross-sectional study that aimed to evaluate the prevalence of LBP and the various risk factors for LBP in young adult Indians.

\section{Materials and Methods}

A cross-sectional study was employed according to the requirements of regulatory authorities and with the permission from the local Institutional Ethics Committee. A total of 1,532 young adults aged between 18 and 35 years were enrolled. The study was conducted among coaching institutes of Indian Administrative Service aspirants and medical postgraduate aspirants in Delhi from August to November 2014. A detailed questionnaire collected data regarding the subjects' sociodemographic profiles assessed using the modified Kuppuswamy scale; smoking (regular smoking was defined as someone who smoked 100 cigarettes in their lifetime and currently smoked cigarettes daily or some days [nondaily]), alcoholism (regular alco- holism was defined as five drinks for men and four drinks for women and must be consumed on one occasion at least once in a 2-week period), and traveling history; diet; time spent studying per day; place of study; posture while studying (walking, sitting in a chair and forward bending, sitting in a chair with back support, sitting on the floor with back support, and sitting on the floor without back support); frequency of weightlifting; sports activities (strenuous activities included swimming laps, aerobics, calisthenics, running, jogging, basketball, cycling on hills, and racquetball and moderate exercises included brisk walking, golf, volleyball, cycling on level streets, recreational tennis, and softball). Frequency and type of sport, history of LBP, factors that aggravate and relieve LBP, frequency of wearing heels, history of osteoporosis, history of spine problems, whether LBP limits daily, strenuous, or social activities, whether LBP is aggravated by the number of study hours, history of emotional depression, presence of monotony, satisfaction in current employment position, family history of spine problems, or spinal surgery. Anthropometric measurements, including height and weight, were measured, and BMI was calculated. Pain was assigned a score of $0-100$. After obtaining ethical permission, all subjects were requested to complete the questionnaire in the presence of an investigator. Informed verbal consent was obtained from all study participants. The data were analyzed using the SPSS ver. 12 (SPSS Inc., Chicago, IL, USA). Percentages and proportions were calculated. The chi-square test was used for categorical variables. Logistic regression analysis was performed using the stepwise, forward entry method, and significant risk factors were examined using significance, standard error, 95\% confidence intervals, and Wald test.

\section{Results}

Of the 1,532 subjects, 1,355 (88.4\%) submitted completed questionnaires; the remainder were incomplete, and hence, were excluded from the study. Moreover, the response rate was considered to be good. Among the included subjects, 741 (54.7\%) were males and 614 (45.3\%) were females. Most subjects (90.6\%) were aged 20-29 years (mean, 24.49 years; range, 18-35 years). More than half (54.7\%) of the study population was non-vegetarian and the rest (45.3\%) were vegetarians. The majority $(78.8 \%)$ belonged to the northern part of the country. Overall, 9.7\% of the subjects belonged to the upper scale, 
$75.8 \%$ belonged to the upper middle, $13.8 \%$ belonged to the lower middle, and $0.7 \%$ belonged to the upper lower scale as per the modified Kuppuswamy scale for the socioeconomic status. Smokers and alcoholics constituted $10.6 \%$ and $11.5 \%$ of the study population, respectively In terms of coffee intake, $69.2 \%$ reported occasional, $16.9 \%$ reported regular, and $13.9 \%$ reported no coffee consumption. Of the 1,355 subjects, $15.6 \%$ were married and $84.6 \%$ were unmarried. We found that LBP is precipitated by studying for $>5$ hours on an average $(p<0.05)$. The LBP prevalence was $42.4 \%$ per year and $22.8 \%$ per week. Pain was assigned a score of $0-100$ and categorized into $<10$, $10-30,30-50$ and $>50$. Scores of $<10$ were considered to be insignificant and scores of $>10$ were considered to be significant; $94.1 \%$ ( 1,011 of 1,074 subjects) had scores of $<10$. Approximately one in five $(20.6 \%)$ patients reported limitations of daily activities that resulted from LBP and $14.4 \%$ felt emotionally depressed because of LBP. In total, $52 \%$ subjects were satisfied with their current position compared with $48 \%$ who were not. Job monotony was reported by $31.9 \%$ of our subjects and stress was reported by $24.2 \%$ of subjects. The frequencies for other measured variables are depicted in Tables 1 and 2 .

Table 1. Sociodemographic profile

\begin{tabular}{lcc}
\hline Parameter & Frequency & Percentage \\
Sex & & \\
\hline Male & 741 & 54.7 \\
\hline Female & 614 & 45.3 \\
\hline State & & \\
\hline North & 1,068 & 78.8 \\
\hline South & 200 & 14.8 \\
\hline East & 25 & 1.8 \\
\hline West & 62 & 4.6 \\
\hline Food habits & & \\
\hline Vegetarian & 614 & 45.3 \\
\hline Non-vegetarian & 741 & 54.7 \\
\hline Marital status & & 84.3 \\
\hline Unmarried & 1,142 & 15.7 \\
\hline Married & 213 & 0.7 \\
\hline Socioeconomic status & 187.8 \\
\hline Upper & 131 & 9.7 \\
\hline Upper middle & 1,027 & 75.8 \\
\hline Lower middle & 107 & \\
\hline Upper lower & & \\
\hline
\end{tabular}

Table 2. Common risk factors for low back pain

\begin{tabular}{lcc} 
Parameter & Frequency & Percentage \\
Smoking & & \\
Yes & 144 & 10.6 \\
\hline No & 1,211 & 89.4 \\
\hline Alcohol intake & & \\
\hline Yes & 156 & 11.5 \\
\hline No & 1,199 & 88.5 \\
\hline Coffee intake & & \\
\hline Regular & 229 & 16.9 \\
\hline Occasional & 938 & 69.2 \\
\hline Never & 188 & 13.9 \\
\hline
\end{tabular}

Mode of travel

\begin{tabular}{|lrr|}
\hline Car & 44 & 3.2 \\
\hline Two wheeler & 90 & 6.6 \\
\hline Standing in metro & 584 & 43.1 \\
\hline Sitting in metro & 99 & 7.3 \\
\hline Standing in bus & 54 & 4.0 \\
\hline Sitting in bus & 15 & 1.1 \\
Walking & 409 & 30.2 \\
\hline
\end{tabular}

Time of travel

\begin{tabular}{lrr}
$<15$ min & 594 & 43.8 \\
\hline $15-30$ min & 318 & 23.5 \\
\hline $30-60$ min & 276 & 20.4 \\
$>1 \mathrm{hr}$ & 167 & 12.3 \\
\hline Weight lifting & & \\
\hline Regular & 149 & 11.0 \\
\hline Occassional & 558 & 41.2 \\
\hline Never & 648 & 47.8 \\
\hline Heels & & \\
\hline Yes & 13 & 1.0 \\
\hline No & 325 & 24.0 \\
\hline Occassional & 1,017 & 75.1 \\
\hline Spine problem & & \\
\hline Yes & 40 & 3.0 \\
\hline No & 1,315 & 97.0 \\
\hline
\end{tabular}

Strenuous exercise

\begin{tabular}{crr} 
Yes & 296 & 21.8 \\
\hline No & 1,059 & 78.2 \\
\hline Satisfaction of current position & & \\
Yes & 704 & 52.0 \\
No & 651 & 48.0 \\
\hline
\end{tabular}


Table 2. Continued

\begin{tabular}{lcc} 
Parameter & Frequency & Percentage \\
Monotony & & \\
Yes & 432 & 31.9 \\
\hline No & 923 & 68.1 \\
\hline Stress & & \\
Yes & 328 & 24.2 \\
No & 1,027 & 75.8 \\
\hline Family history & & \\
Yes & 429 & 31.7 \\
\hline No & 926 & 68.3 \\
\hline
\end{tabular}

Results indicated that the following factors were associated with LBP in young adults: marital status, previous history of spine problems, strenuous exercise, satisfaction in current employment position, monotony, stress, number of daily study hours, and family history of spine problems (Tables 3, 4). Satisfaction with current employment position, monotony, stress, and family history of spine problems were identified as significant predictors of LBP using logistic regression (Table 5). In contrast, age, sex, smoking, alcoholism, coffee intake, mode and duration of travel, diet, frequency of weightlifting, wearing heels, studying posture, and frequency and type of sports activities were not associated with LBP.

Table 3. Statistically significant risk factors for low back pain

\begin{tabular}{|c|c|c|c|c|c|c|}
\hline \multirow{2}{*}{ Parameter } & \multicolumn{4}{|c|}{ Pain score } & \multirow{2}{*}{ Total } & \multirow{2}{*}{$p$-value } \\
\hline & $<10$ & $10-30$ & $30-50$ & $>50$ & & \\
\hline Marital status & & & & & & $0.003^{\mathrm{a})}$ \\
\hline Unmarried & 876 & 28 & 19 & 221 & 1,144 & \\
\hline Married & 135 & 11 & 5 & 60 & 211 & \\
\hline Past history of spine problem & & & & & & $0.002^{\mathrm{a})}$ \\
\hline Yes & 15 & 2 & 7 & 16 & 40 & \\
\hline No & 996 & 37 & 17 & 265 & 1,315 & \\
\hline Strenuous exercise & & & & & & $0.000^{\mathrm{al}}$ \\
\hline Yes & 124 & 21 & 9 & 142 & 296 & \\
\hline No & 887 & 18 & 15 & 139 & 1,059 & \\
\hline Satisfaction of current position & & & & & & $0.011^{\mathrm{a})}$ \\
\hline Yes & 501 & 28 & 10 & 165 & 704 & \\
\hline No & 510 & 11 & 14 & 116 & 651 & \\
\hline Monotony & & & & & & $0.000^{\mathrm{al}}$ \\
\hline Yes & 287 & 21 & 3 & 121 & 432 & \\
\hline No & 724 & 18 & 21 & 160 & 923 & \\
\hline Stress & & & & & & $0.000^{\mathrm{a})}$ \\
\hline Yes & 187 & 9 & 10 & 122 & 328 & \\
\hline No & 824 & 30 & 14 & 159 & 1,027 & \\
\hline Family history & & & & & & $0.014^{\mathrm{a})}$ \\
\hline Yes & 298 & 17 & 8 & 106 & 429 & \\
\hline No & 713 & 22 & 16 & 175 & 926 & \\
\hline No. of study hours & & & & & & $0.016^{\mathrm{a})}$ \\
\hline$<5 \mathrm{hr}$ & 982 & 23 & 17 & 257 & 1,279 & \\
\hline$\geq 5 \mathrm{hr}$ & 29 & 16 & 7 & 24 & 76 & \\
\hline Total & 1,011 & 39 & 24 & 281 & 1,355 & \\
\hline
\end{tabular}

Visual analog scale (VAS) $<10$ is considered as insignificant and VAS $>10$ is considered as significant. ${ }^{a)} p<0.001$; statistically significant. 
Table 4. Statistically insignificant factors for low back pain

\begin{tabular}{|c|c|c|c|c|c|c|}
\hline \multirow{2}{*}{ Parameter } & \multicolumn{4}{|c|}{ Pain score } & \multirow{2}{*}{ Total } & \multirow{2}{*}{$p$-value } \\
\hline & $<10$ & $10-30$ & $30-50$ & $>50$ & & \\
\hline Coffee intake & & & & & & 0.622 \\
\hline Regular & 93 & 15 & 15 & 106 & 229 & \\
\hline Occasional & 803 & 16 & 6 & 113 & 938 & \\
\hline Never & 115 & 8 & 3 & 62 & 188 & \\
\hline Travel time & & & & & & 0.693 \\
\hline$<15 \min$ & 452 & 8 & 12 & 122 & 594 & \\
\hline $15-30 \mathrm{~min}$ & 239 & 13 & 4 & 62 & 318 & \\
\hline $30-60 \mathrm{~min}$ & 203 & 7 & 5 & 61 & 276 & \\
\hline$>60 \min$ & 117 & 11 & 3 & 36 & 167 & \\
\hline Mode of travel & & & & & & 1.863 \\
\hline Car & 17 & 9 & 7 & 11 & 44 & \\
\hline 2 wheeler & 61 & 11 & 3 & 19 & 94 & \\
\hline Standing in metro/bus & 531 & 8 & 1 & 138 & 678 & \\
\hline Sitting in metro/bus & 81 & 6 & 6 & 35 & 128 & \\
\hline Walking & 321 & 5 & 7 & 78 & 411 & \\
\hline Heels & & & & & & 0.065 \\
\hline Yes & 4 & 5 & 1 & 3 & 13 & \\
\hline No & 221 & 23 & 13 & 68 & 325 & \\
\hline Occasional & 786 & 11 & 10 & 210 & 1017 & \\
\hline Total & 1,011 & 39 & 24 & 281 & 1,355 & \\
\hline
\end{tabular}

Visual analog scale (VAS) $<10$ is considered as insignificant and VAS $>10$ is considered as significant.

Table 5. Logistic regression analysis of significant factors for low back pain

\begin{tabular}{|c|c|c|c|c|}
\hline \multirow{2}{*}{ Variable } & \multirow{2}{*}{ Standard error } & \multirow{2}{*}{ Significance } & \multicolumn{2}{|c|}{ 95.0\% Confidence intervals } \\
\hline & & & Upper & Lower \\
\hline Satisfaction of current position & 0.160 & 0.013 & 1.088 & 2.039 \\
\hline Monotony & 0.166 & 0.031 & 1.065 & 1.849 \\
\hline Stress & 0.188 & 0.025 & 1.978 & 2.046 \\
\hline Family history & 0.169 & 0.042 & 1.359 & 2.664 \\
\hline Past history of spine problem & 0.435 & 0.6 & 0.922 & 5.065 \\
\hline
\end{tabular}

\section{Discussion}

Various studies [1-3] reported that LBP is one of the most common causes of hospital visits and that it is the leading cause of activity limitations and work absences in many parts of the world. LBP poses a significant economic threat to the individual, family, workplace, and society. Initially considered to be a problem confined to developed countries, studies have now revealed an increasing preva- lence in developing countries [15,16]. Although LBP can manifest at any age, LBP prevalence is the highest in the third decade of life [17]. LBP occurrence at an early age can cause disease progression, resulting in chronic LBP that has the potential to decrease an individual's quality of life [8]. Being a common health issue that affects all age groups, LBP and its risk factors have been evaluated by various authors internationally. However, data pertaining to the prevalence and risk factors for LBP in Indian 
subjects is scarce, particularly in young adults. This study, which included 1355 young adults, was unique as it not only examined LBP prevalence in young adults in Delhi, India, but also analyzed its potential risk factors. Recommendations are provided herein to prevent the modifiable risk factors with which one can expect a reduction in LBP incidence and prevalence.

According to Hestbaek et al. [18], the annual LBP prevalence in young adults is $32.4 \%$ compared with $42.4 \%$ annually, as observed in the current study. This study demonstrated that there is no sex predilection for LBP occurrence, which is consistent with several studies [19]. Furthermore, our results differ from those of Linton et al. [20] and Thomas et al. [21], which demonstrated a higher incidence in females and who also develop chronic backache compared with males. A meta-analysis by Hoy et al. [22] also showed an increased prevalence in females. Shiri et al. [23] conducted a meta-analysis and found that smokers have a higher prevalence and LBP incidence than non-smokers and that the pain is stronger in adolescents than in adults. Our study results were contrasting, revealing no significant difference in LBP occurrence in smokers and alcoholics compared with non-smokers and non-alcoholics. Similar to the results of Currie et al. [24], our analysis did not demonstrate an association between coffee intake and LBP. Although few studies suggested that BMI is a weak factor in LBP occurrence, a study by Webb et al. [9] showed that higher BMI is associated with an increased LBP incidence. The results obtained in our study showed that BMI did not have a significant impact in LBP development. With regard to the marital status, an increased LBP incidence in married participants was contemplated compared with unmarried subjects.

Static muscle load and flexion of the lumbar spine have been postulated as risk factors for LBP development; thus, prolonged sitting or sitting in an abnormal posture can aggravate LBP [25]. We found that posture while studying had no effect on LBP occurrence; however, the number of daily hours spent studying had a significant association with LBP. We ascertained that LBP is precipitated by studying for $>5$ hours on an average $(p<0.05)$. We analyzed the mode and time of travel to the institutes and detected that there was no significant correlation between these variables and LBP. Further analysis aimed to examine the association between LBP and posture while traveling (standing vs. sitting), but results revealed no significant correlation between these parameters.
The role of psychosocial factors in LBP development has been emphasized in various studies. Nuwayhid et al. [11] showed that there was no correlation between LBP and job dissatisfaction, whereas other authors [12] demonstrated a significant impact of job dissatisfaction on LBP. Moreover, dissatisfaction with one's job or position can lead to the progression of acute LBP to chronic LBP [26]. In our study, LBP prevalence was significantly higher in the dissatisfied group $(p<0.05)$. A systemic review by Hoogendoorn et al. [13], which evaluated psychosocial factors in the workplace, showed that job monotony increases the LBP prevalence. Similarly, the $31.9 \%$ of our subjects who reported job monotony had an increased LBP incidence $(p<0.01)$. Atkinson et al. [14] postulated that stress can precipitate LBP and can cause chronic LBP. Stress had a statistically significant correlation with LBP. Previous research revealed LBP recurrence, which can eventually become chronic [26]. In this study, $3 \%$ of subjects had at least one LBP recurrence in the past year, and this recurrence was associated with LBP $(p<0.01)$. In their study of 3,042 factory workers, Matsui et al. [27] concluded that LBP is prevalent in subjects with a positive family history in parents or siblings. Similar to this, our study also showed a statistically significant correlation between a positive family history and LBP $(p<0.01)$. Although studies $[6,28]$ have demonstrated an increased association of sports and athletic activities with LBP, our study did not show an association between LBP and any type of sport or duration of sports activities. Similarly, our study did not find a significant correlation between LBP and frequency of wearing heels or weightlifting. Some studies $[29,30]$ demonstrated that socioeconomic status has an inverse association with LBP; however, we did not find any significant association between these two factors.

This study identified family history as a non-modifiable risk factor, and the number of study hours, marital status, previous history of spine problems, strenuous exercise, job satisfaction, monotony, and stress as modifiable risk factors for LBP in a young Indian population. Satisfaction of one's current position, family history of spine problems, stress, and monotony appeared to be the major contributing factors for LBP development in young Indian adults, as indicated by logistic regression analysis. Lifestyle modifications such as adequate rest, relaxation [14], and recreation can reduce and modify stress and monotony, thereby preventing LBP development. The health and economic status of young adults play a vital role in devel- 
oping countries such as India. LBP occurrence in the early stages of life increases the risk for chronic, reoccurring LBP, which has the potential to reduce the efficiency of the young population, which in turn may affect productivity.

The limitations of our study included the fact that it was conducted in young adults who were preparing for their entrance examinations. At the time of the study, these individuals often studied for long periods of time, which could be a major contributing factor to LBP occurrence. Thus, these subjects would have likely experienced high stress levels and monotony, which may have exacerbated LBP. Our study did not include sedentary lifestyle as a risk factor for LBP. Although the study sample included subjects from various parts of the country, the majority was from north India, which could be a limitation. Because this study was questionnaire based, the students were not asked to provide details regarding smoking and alcoholism, which could explain why our results contrasted those of other studies. Finally, as this was a cross-sectional study, we could not assess LBP progression in these subjects, except for in a very small number of subjects who returned to our clinic for evaluation of the problem.

\section{Conclusions}

This study, conducted among a young adult Indian population, revealed that Indian youth are prone to developing LBP, which aligns with published Western literature. The study also identified various modifiable and non-modifiable risk factors for LBP in young adults. Identification of these risk factors at an early stage will prevent the progression of acute LBP to chronic LBP. As chronic LBP has the potential to curb individual quality of life and increase economic burden, creating awareness about the modifiable risk factors in young adult populations may lead to lifestyle modifications, thereby improving their quality of life and increasing productivity.

\section{Conflict of Interest}

No potential conflict of interest relevant to this article was reported.

\section{References}

1. Andersson GB. Epidemiological features of chronic low-back pain. Lancet 1999;354:581-5.
2. Papageorgiou AC, Croft PR, Ferry S, Jayson MI, Silman AJ. Estimating the prevalence of low back pain in the general population: evidence from the South Manchester Back Pain Survey. Spine (Phila Pa 1976) 1995;20:1889-94.

3. Hart LG, Deyo RA, Cherkin DC. Physician office visits for low back pain: frequency, clinical evaluation, and treatment patterns from a U.S. national survey. Spine (Phila Pa 1976) 1995;20:11-9.

4. Balague F, Nordin M, Skovron ML, Dutoit G, Yee A, Waldburger M. Non-specific low-back pain among schoolchildren: a field survey with analysis of some associated factors. J Spinal Disord 1994;7:374-9.

5. Diepenmaat AC, van der Wal MF, de Vet HC, Hirasing RA. Neck/shoulder, low back, and arm pain in relation to computer use, physical activity, stress, and depression among Dutch adolescents. Pediatrics 2006;117:412-6.

6. Kujala UM, Taimela S, Erkintalo M, Salminen JJ, Kaprio J. Low-back pain in adolescent athletes. Med Sci Sports Exerc 1996;28:165-70.

7. Fairbank JC, Pynsent PB, Van Poortvliet JA, Phillips $\mathrm{H}$. Influence of anthropometric factors and joint laxity in the incidence of adolescent back pain. Spine (Phila Pa 1976) 1984;9:461-4.

8. Harreby M, Neergaard K, Hesselsoe G, Kjer J. Are radiologic changes in the thoracic and lumbar spine of adolescents risk factors for low back pain in adults? A 25-year prospective cohort study of 640 school children. Spine (Phila Pa 1976) 1995;20:2298-302.

9. Webb R, Brammah T, Lunt M, Urwin M, Allison T, Symmons D. Prevalence and predictors of intense, chronic, and disabling neck and back pain in the UK general population. Spine (Phila Pa 1976) 2003;28: 1195-202.

10. Battie MC, Videman T, Gibbons LE, Fisher LD, Manninen H, Gill K. 1995 Volvo Award in clinical sciences. Determinants of lumbar disc degeneration: a study relating lifetime exposures and magnetic resonance imaging findings in identical twins. Spine (Phila Pa 1976) 1995;20:2601-12.

11. Nuwayhid IA, Stewart W, Johnson JV. Work activities and the onset of first-time low back pain among New York City fire fighters. Am J Epidemiol 1993;137:53948.

12. Papageorgiou AC, Macfarlane GJ, Thomas E, Croft PR, Jayson MI, Silman AJ. Psychosocial factors in the 
workplace: do they predict new episodes of low back pain? Evidence from the South Manchester Back Pain Study. Spine (Phila Pa 1976) 1997;22:1137-42.

13. Hoogendoorn WE, van Poppel MN, Bongers PM, Koes BW, Bouter LM. Systematic review of psychosocial factors at work and private life as risk factors for back pain. Spine (Phila Pa 1976) 2000;25:2114-25.

14. Atkinson JH, Slater MA, Grant I, Patterson TL, Garfin SR. Depressed mood in chronic low back pain: relationship with stressful life events. Pain 1988;35:4755.

15. Hoy D, Toole MJ, Morgan D, Morgan C. Low back pain in rural Tibet. Lancet 2003;361:225-6.

16. Jin K, Sorock GS, Courtney TK. Prevalence of low back pain in three occupational groups in Shanghai, People’s Republic of China. J Safety Res 2004;35:23-8.

17. Kopec JA, Sayre EC, Esdaile JM. Predictors of back pain in a general population cohort. Spine (Phila Pa 1976) 2004;29:70-7.

18. Hestbaek L, Leboeuf-Yde C, Kyvik KO. Are lifestylefactors in adolescence predictors for adult low back pain? A cross-sectional and prospective study of young twins. BMC Musculoskelet Disord 2006;7:27.

19. Smith BH, Elliott AM, Hannaford PC, Chambers WA, Smith WC. Factors related to the onset and persistence of chronic back pain in the community: results from a general population follow-up study. Spine (Phila Pa 1976) 2004;29:1032-40.

20. Linton SJ, Hellsing AL, Hallden K. A populationbased study of spinal pain among 35-45-year-old individuals. Prevalence, sick leave, and health care use. Spine (Phila Pa 1976) 1998;23:1457-63.

21. Thomas E, Silman AJ, Croft PR, Papageorgiou AC, Jayson MI, Macfarlane GJ. Predicting who develops chronic low back pain in primary care: a prospective study. BMJ 1999;318:1662-7.

22. Hoy D, Brooks P, Blyth F, Buchbinder R. The Epidemiology of low back pain. Best Pract Res Clin Rheumatol 2010;24:769-81.

23. Shiri R, Karppinen J, Leino-Arjas P, Solovieva S, Viikari-Juntura $\mathrm{E}$. The association between smoking and low back pain: a meta-analysis. Am J Med 2010; 123:87.e7-35.

24. Currie SR, Wilson KG, Gauthier ST. Caffeine and chronic low back pain. Clin J Pain 1995;11:214-9.

25. Hedman TP, Fernie GR. Mechanical response of the lumbar spine to seated postural loads. Spine (Phila Pa 1976) 1997;22:734-43.

26. Enthoven P, Skargren E, Oberg B. Clinical course in patients seeking primary care for back or neck pain: a prospective 5-year follow-up of outcome and health care consumption with subgroup analysis. Spine (Phila Pa 1976) 2004;29:2458-65.

27. Matsui H, Maeda A, Tsuji H, Naruse Y. Risk indicators of low back pain among workers in Japan: association of familial and physical factors with low back pain. Spine (Phila Pa 1976) 1997;22:1242-7.

28. Sward L, Eriksson B, Peterson L. Anthropometric characteristics, passive hip flexion, and spinal mobility in relation to back pain in athletes. Spine (Phila $\mathrm{Pa}$ 1976) 1990;15:376-82.

29. Croft PR, Rigby AS. Socioeconomic influences on back problems in the community in Britain. J Epidemiol Community Health 1994;48:166-70.

30. Latza U, Kohlmann T, Deck R, Raspe H. Influence of occupational factors on the relation between socioeconomic status and self-reported back pain in a population-based sample of German adults with back pain. Spine (Phila Pa 1976) 2000;25:1390-7. 